\title{
Effects of different recovery methods on postboxing sparring fatigue substances and stress hormones
}

\author{
Duan Tianlong ${ }^{1,2}$, Young-Je Sim ${ }^{1, *}$ \\ 'Department of Physical Education, Kunsan National University, Gunsan, Korea \\ ${ }^{2}$ School of Physical Education, Qingdao University, Qingdao, Shandong, China
}

This study aimed to investigate the effects of static rest, massage, aromatherapy, and acupoint acupressure on the levels of fatigue substances and stress hormones produced after a session of boxing sparring. The study was conducted on female adolescent boxers $(n=12)$ who underwent four recovery methods with a 7-day rest period between each session. The order of these methods was decided randomly. Prior to each method, the participants performed five rounds of 4-min boxing sparring, and the maximal intensity was set as $70 \%-80 \%$ of the maximal heart rate. The effects of the four recovery methods on the blood levels of fatigue substances and stress hormones after boxing sparring were investigated. Static rest, massage, aromatherapy, and acupoint acupressure significantly decreased the lactic acid levels. The creatine phosphokinase levels decreased in the aromatherapy and acupoint acupressure groups, while the lactate dehydrogenase levels significantly decreased in the massage, aromatherapy, and acupoint acu- pressure groups. Further, the levels of stress hormones, cortisol, and epinephrine, showed no significant changes after massage and acupoint acupressure. However, a significant decrease in the cortisol level was observed in the aromatherapy group and an increasing trend was observed in the cortisol level in the static rest group. The adrenocorticotropic hormone level significantly decreased in the aromatherapy group and showed a decreasing trend after the participants received massage or acupoint acupressure. High-intensity exercise results in not only physical, but also psychological fatigue. Massage and aromatherapy can improve the physical and psychological stabilities and performances of athletes.

Keywords: Boxing sparring, Aromatherapy, Acupoint acupressure, Massage, Fatigue substance, Stress hormone

\section{INTRODUCTION}

As integration of science with sports is becoming more common, sports is approached from different perspectives to develop efficient training methods and identify ways to reduce fatigue and stress. Several sports investigators and coaches have become interested in effectively eliminating fatigue substances in the body and maximizing recovery from fatigue to improve sports performance.

The main reasons for postexercise fatigue are insufficient storage of nutrients, difficulty in neurotransmission, and accumulation of metabolites secondary to energy metabolism. Accumulation of lactic acid, which is produced by insufficient supply of oxygen during exercise, causes muscle fatigue and consequentially affects sports performance (Tesch, 1980). Creatine phosphokinase (CPK) and lactate dehydrogenase (LDH), which accumulate in the blood after prolonged or high-intensity exercises, are also important indicators of muscle fatigue (Banfi et al., 2009). Since outstanding recovery is directly related to sports performance, finding effective ways to remove fatigue substances and minimize changes in muscle damage markers, such as CPK and LDH, is markedly important (Cha et al., 2006; Rowsell et al., 2009).

Exercise exerts stress on the body, and the level of stress depends on the duration or intensity of the exercise. Disturbances in homeostasis due to exercise require a new level of adaptation that would activate the neuroendocrine response of the body. The sympathetic nerves and adrenal glands are especially important with respect to responsiveness to exercise stress. As the activity of the sympathetic nerves increases secondary to exercise, increased me-
${ }^{*}$ Corresponding author: Young-Je Sim (iD https://orcid.org/0000-0002-9574-3135 Department of Physical Education, Kunsan National University,

558 Daehak-ro, Gunsan 54150, Korea

E-mail: simyoungje@gmail.com

Received: December 12, 2018 / Accepted: January 17, 2019
This is an Open Access article distributed under the terms of the Creative Commons Attribution Non-Commercial License (http://creativecommons.org/licenses/by-nc/4.0/) which permits unrestricted non-commercial use, distribution, and reproduction in any medium, provided the original work is properly cited. 
tabolism causes release of norepinephrine from the sympathetic fibers, which increases the respiratory rate. Epinephrine is released from the adrenal glands and has significant effects on metabolism (Christensen and Galbo, 1983). The blood cortisol levels are also increased following psychological/physiological stress. Exercise stimulates the release of adrenocorticotropic hormone (ACTH), which acts on the adrenal glands to stimulate cortisol production (O'Connor et al., 1989).

Alternative and complementary medicine strategies, including massage, electrical stimulation, ultrasonic wave, meridian, meditation, and aromatherapy, have been proposed to overcome exercise-induced fatigue and stress. Massage is a very important recovery or prevention method (Goats, 1994; Hemmings et al., 2000; Mori et al., 2004) and is used in diverse fields. The medical association is currently focusing on aromatherapy, in which aromatic scents travel through the olfactory system, skin, lungs, and circulation to reach the limbic system, where they stimulate the production of chemicals to improve the healing rate and reduce stress levels (Son et al., 2001).

In this study, alternative and complementary medicine strategies, including static rest, massage, aromatherapy, and acupoint acupressure, were used after high-intensity boxing sparring to reduce fatigue and stress. Their effects on the levels of fatigue substances and stress hormones were investigated, and the results may be used as a basis to develop effective methods to recover from fatigue.

\section{MATERIALS AND METHODS}

Twelve female adolescent boxers, currently enrolled in J Athletic School in Jenam, Shandong, China, participated in this study. The participants had more than 2 years of boxing experience, who did not have any medical history, understood the explanation of our study's purpose, and voluntarily gave consent to participate. The participants' characteristics are shown in Table 1.

To ensure maximal performance of the participants, the duration of each boxing round was set to $4 \mathrm{~min}$, which is relatively longer than that of real boxing match rounds, and a total of five

Table 1. Physical characteristics of the subjects $(n=12)$

\begin{tabular}{lc}
\hline Characteristic & Mean \pm SD \\
\hline Age $(\mathrm{yr})$ & $16.50 \pm 1.00$ \\
Height $(\mathrm{cm})$ & $165.33 \pm 6.36$ \\
Weight $(\mathrm{kg})$ & $53.58 \pm 16.04$ \\
Career $(\mathrm{yr})$ & $3.46 \pm 0.58$ \\
\hline
\end{tabular}

$\mathrm{SD}$, standard deviation. rounds were performed. A break of 1 min was allowed between the rounds. The condition of the participants was monitored using a heart rate monitor watch to maintain a maximal heart rate of $70 \%-80 \%$ (Table 2).

To minimize interaction among the different recovery methods (static rest, massage, aromatherapy, and acupoint acupressure), a 7-day break was provided for all participants. The recovery sessions were performed $20 \mathrm{~min}$ after the boxing sparring sessions. The order of the recovery methods was decided randomly, and the details are presented in Table 3.

Moreover, blood samples were collected from the participants immediately after the exercise and the recovery sessions. The blood was drawn by a nurse from the medical laboratory in $\mathrm{Q}$ Hospital from the participants' cubital vein. The collected blood sample was centrifuged at 3,000 rpm for $30 \mathrm{~min}$ and stored at a $-70^{\circ} \mathrm{C}$ fridge. All variable analyses were performed at the medical laboratory, and the participants' lactic acid, CPK, LDH, cortisol, epinephrine, norepinephrine, and ACTH levels were measured.

All data analyses in this study were conducted using the IBM SPSS Statistics ver. 22.0 (IBM Co., Armonk, NY, USA). Means and standard deviations for all measurements were calculated, and repeated measures analysis of variance was performed to determine the significance of the different recovery methods. The significance level was set at 0.05 .

\section{RESULTS}

Changes in the lactic acid level are presented in Table 4. Al-

Table 2. Boxing sparring program

\begin{tabular}{lclc}
\hline Exercise & $\begin{array}{c}\text { Intensity } \\
\text { (maximal heart rate) }\end{array}$ & Program & $\begin{array}{c}\text { Time } \\
\text { (min) }\end{array}$ \\
\hline Warm-up & $40 \%-50 \%$ & Stretching & 15 \\
Sparring & $70 \%-80 \%$ & $\begin{array}{l}\text { Five 4-min rounds (1-min break between } \\
\text { rounds) }\end{array}$ & 24 \\
\hline
\end{tabular}

Table 3. Recovery methods

\begin{tabular}{lc}
\hline Recovery type & \multicolumn{1}{c}{ Method } \\
\hline Static rest & $\begin{array}{c}20 \text { min of static rest while sitting in a comfortable } \\
\text { position } \\
20 \text { min of massage by a masseuse while sitting on a } \\
\text { chair to relax the muscles, progressing from the } \\
\text { uassage }\end{array}$ \\
$\begin{array}{l}20 \text { min of inhalation of essential oil while sitting } \\
\text { Aromatherapy (rosemary) } \\
\text { Acupoint acupressure }\end{array}$ & $\begin{array}{c}20 \text { min of acupoint acupressure performed by a } \\
\text { specialist in the order of the upper limbs, lower } \\
\text { limbs, and lower back }\end{array}$ \\
\hline
\end{tabular}


Table 4. Changes in the lactic acid level (mg/dL) from postexercise to postrecovery in each group

\begin{tabular}{lllc}
\hline Group & Postexercise & Postrecovery & $F(P$-value $)$ \\
\hline Static rest & $50.91 \pm 11.46$ & $46.95 \pm 12.21$ & $17.83(0.002)$ \\
Massage & $61.41 \pm 18.94$ & $44.05 \pm 8.70$ & $17.99(0.002)$ \\
Aromatherapy & $50.82 \pm 11.25$ & $36.64 \pm 6.82$ & $20.89(0.001)$ \\
Acupoint acupressure & $56.98 \pm 22.60$ & $38.29 \pm 9.92$ & $18.46(0.002)$ \\
\hline
\end{tabular}

Values are presented as mean \pm standard deviation.

$F_{\text {group } * \text { time }}=4.29(0.052)$.

Table 5. Changes in the creatine phosphokinase level (U/L) from postexercise to postrecovery in each group

\begin{tabular}{lrrr}
\hline Group & \multicolumn{1}{c}{ Postexercise } & Postrecovery & \multicolumn{1}{c}{$F(P$-value $)$} \\
\hline Static rest & $83.40 \pm 15.14$ & $83.08 \pm 16.34$ & $0.35(0.568)$ \\
Massage & $122.91 \pm 43.54$ & $117.65 \pm 38.31$ & $1.28(0.288)$ \\
Aromatherapy & $83.31 \pm 15.07$ & $75.00 \pm 15.56$ & $24.22(0.001)$ \\
Acupoint acupressure & $139.79 \pm 90.43$ & $134.68 \pm 92.43$ & $6.52(0.031)$ \\
\hline
\end{tabular}

Values are presented as mean \pm standard deviation.

$F_{\text {group } * \text { time }}=5.48(0.030)$.

though the interaction between the group and the time period was slightly higher than the significance level, it was determined to be present. Therefore, a paired sample $t$-test was performed in each group. The static rest, massage, aromatherapy, and acupoint acupressure groups showed a significant decrease in the lactic acid level from $50.91 \pm 11.46 \mathrm{mg} / \mathrm{dL}$ postexercise to $46.95 \pm 12.21$ $\mathrm{mg} / \mathrm{dL}$ postrecovery $(P<0.01)$, from $61.41 \pm 18.94 \mathrm{mg} / \mathrm{dL}$ postexercise to $44.05 \pm 8.70 \mathrm{mg} / \mathrm{dL}$ postrecovery $(P<0.01)$, from $50.82 \pm 11.25 \mathrm{mg} / \mathrm{dL}$ postexercise to $36.64 \pm 6.82 \mathrm{mg} / \mathrm{dL}$ postrecovery $(P<0.01)$, and from $56.98 \pm 22.60 \mathrm{mg} / \mathrm{dL}$ postexercise to $38.29 \pm 9.92 \mathrm{mg} / \mathrm{dL}$ postrecovery $(P<0.01)$, respectively.

Changes in the CPK level are presented in Table 5. An interaction between the group and the time period was observed $(P<$ $0.05)$. The static rest and massage groups did not show a significant decrease in the CPK level from $83.40 \pm 15.14 \mathrm{U} / \mathrm{L}$ postexercise to $83.08 \pm 16.34 \mathrm{U} / \mathrm{L}$ postrecovery and from $122.91 \pm 43.54$ $\mathrm{U} / \mathrm{L}$ postexercise to $117.65 \pm 38.31 \mathrm{U} / \mathrm{L}$ postrecovery, respectively. In contrast, the aromatherapy and acupoint acupressure groups showed a significant decrease in the CPK level from 83.31 \pm 15.07 $\mathrm{U} / \mathrm{L}$ postexercise to $75.00 \pm 15.56 \mathrm{U} / \mathrm{L}$ postrecovery $(P<0.01)$ and from $139.79 \pm 90.43 \mathrm{U} / \mathrm{L}$ postexercise to $134.68 \pm 92.43 \mathrm{U} / \mathrm{L}$ postrecovery $(P<0.05)$, respectively.

Changes in the LDH level are presented in Table 6. An interaction between the group and the time period was observed $(P<$ $0.05)$. The static rest group did not show a significant change in the $\mathrm{LDH}$ level from $204.70 \pm 13.84 \mathrm{U} / \mathrm{L}$ postexercise to $201.60 \pm$
Table 6. Changes in the lactate dehydrogenase level from postexercise to postrecovery in each group

\begin{tabular}{lccr}
\hline Group & Postexercise & Postrecovery & \multicolumn{1}{c}{$F(P$-value $)$} \\
\hline Static rest & $204.70 \pm 13.84$ & $201.60 \pm 12.50$ & $1.45(0.259)$ \\
Massage & $220.00 \pm 30.04$ & $208.50 \pm 23.80$ & $7.58(0.022)$ \\
Aromatherapy & $206.70 \pm 16.99$ & $192.00 \pm 17.52$ & $101.24(0.000)$ \\
Acupoint acupressure & $188.60 \pm 20.62$ & $180.10 \pm 23.04$ & $6.74(0.029)$ \\
\hline
\end{tabular}

Values are presented as mean \pm standard deviation.

$F_{\text {group }} *$ time $=5.54(0.029)$.

Table 7. Changes in the cortisol level (nmol/L) from postexercise to postrecovery in each group

\begin{tabular}{lccr}
\hline Group & Postexercise & Postrecovery & \multicolumn{1}{c}{$F(P$-value $)$} \\
\hline Static rest & $591.40 \pm 120.68$ & $636.29 \pm 144.78$ & $3.67(0.088)$ \\
Massage & $572.59 \pm 105.73$ & $564.87 \pm 152.94$ & $0.14(0.722)$ \\
Aromatherapy & $570.24 \pm 102.76$ & $510.14 \pm 104.22$ & $12.05(0.007)$ \\
Acupoint acupressure & $706.48 \pm 120.02$ & $686.56 \pm 174.38$ & $0.79(0.397)$ \\
\hline
\end{tabular}

Values are presented as mean \pm standard deviation.

$F_{\text {group } * \text { time }}=5.08(0.035)$

$12.50 \mathrm{U} / \mathrm{L}$ postrecovery. In contrast, the massage, aromatherapy, and acupoint acupressure groups showed a significant decrease in the $\mathrm{LDH}$ level from $220.00 \pm 30.04 \mathrm{U} / \mathrm{L}$ postexercise to $208.50 \pm$ $23.80 \mathrm{U} / \mathrm{L}$ postrecovery $(P<0.05)$, from $206.70 \pm 16.99 \mathrm{U} / \mathrm{L}$ postexercise to $192.00 \pm 17.55 \mathrm{U} / \mathrm{L}$ postrecovery $(P<0.001)$, and from $188.60 \pm 20.62 \mathrm{U} / \mathrm{L}$ postexercise to $180.10 \pm 23.04 \mathrm{U} / \mathrm{L}$ postrecovery $(P<0.05)$, respectively.

Changes in the cortisol level are presented in Table 7. An interaction between the group and the time period was observed $(P<$ $0.05)$. The static rest group showed an increasing trend in the cortisol level from $591.40 \pm 120.68 \mathrm{nmol} / \mathrm{L}$ postexercise to $636.29 \pm$ $144.78 \mathrm{nmol} / \mathrm{L}$ postrecovery. The massage and acupoint acupressure groups did not show a significant decrease in the cortisol level from $572.59 \pm 105.73 \mathrm{nmol} / \mathrm{L}$ postexercise to $564.87 \pm 152.94$ $\mathrm{nmol} / \mathrm{L}$ postrecovery and from $706.48 \pm 120.02 \mathrm{nmol} / \mathrm{L}$ postexercise to $686.56 \pm 174.38 \mathrm{nmol} / \mathrm{L}$ postrecovery, respectively. In contrast, the aromatherapy group showed a significant decrease from $570.24 \pm 102.76 \mathrm{nmol} / \mathrm{L}$ postexercise to $510.14 \pm 104.22 \mathrm{nmol} / \mathrm{L}$ postrecovery $(P<0.01)$.

Changes in the epinephrine level are presented in Table 8. An interaction between the group and the time period was observed $(P<0.05)$. The static rest, massage, and acupoint acupressure groups did not show a significant change in the epinephrine level from $14.32 \pm 6.27 \mathrm{pg} / \mathrm{mL}$ postexercise to $14.77 \pm 5.94 \mathrm{pg} / \mathrm{mL}$ postrecovery, from $33.16 \pm 35.79 \mathrm{pg} / \mathrm{mL}$ postexercise to $25.52 \pm 22.72$ $\mathrm{pg} / \mathrm{mL}$ postrecovery, and from $37.89 \pm 32.76 \mathrm{pg} / \mathrm{mL}$ postexercise 
Table 8. Changes in the epinephrine level $(\mathrm{pg} / \mathrm{mL})$ from postexercise to postrecovery in each group

\begin{tabular}{lccr}
\hline Group & Postexercise & Postrecovery & $F(P$-value $)$ \\
\hline Static rest & $14.32 \pm 6.27$ & $14.77 \pm 5.94$ & $0.56(0.472)$ \\
Massage & $33.16 \pm 35.79$ & $25.52 \pm 22.72$ & $2.73(0.133)$ \\
Aromatherapy & $13.58 \pm 5.91$ & $8.44 \pm 4.71$ & $10.88(0.009)$ \\
Acupoint acupressure & $37.89 \pm 32.76$ & $31.53 \pm 25.82$ & $0.27(0.619)$ \\
\hline
\end{tabular}

Values are presented as mean \pm standard deviation.

$F_{\text {group } * \text { time }}=4.71(0.042)$.

Table 9. Changes in the norepinephrine level $(\mathrm{pg} / \mathrm{mL})$ from postexercise to postrecovery in each group

\begin{tabular}{llll}
\hline Group & Postexercise & Postrecovery & $F(P$-value $)$ \\
\hline Static rest & $256.21 \pm 114.38$ & $290.37 \pm 119.91$ & $5.11(0.050)$ \\
Massage & $225.89 \pm 371.62$ & $104.75 \pm 67.65$ & $1.05(0.333)$ \\
Aromatherapy & $218.54 \pm 81.47$ & $175.87 \pm 86.34$ & $1.50(0.253)$ \\
Acupoint acupressure & $725.58 \pm 628.65$ & $371.65 \pm 163.58$ & $3.67(0.088)$ \\
\hline
\end{tabular}

Values are presented as mean \pm standard deviation.

$F_{\text {group }} *$ time $=3.57(0.075), F_{\text {group }}=5.37(0.031), F_{\text {time }}=2.92(0.122)$.

to $31.53 \pm 25.82 \mathrm{pg} / \mathrm{mL}$ postrecovery, respectively. In contrast, the aromatherapy group showed a significant decrease in the epinephrine level from $13.58 \pm 5.91 \mathrm{pg} / \mathrm{mL}$ postexercise to $8.44 \pm 4.61$ $\mathrm{pg} / \mathrm{mL}$ postrecovery $(P<0.01)$.

Changes in the norepinephrine level are presented in Table 9. No interaction between the group and the time period was observed. Although no main effect in the time period was observed, significant difference among groups was observed.

Changes in the ACTH level are presented in Table 10. An interaction between the group and the time period was observed $(P<0.05)$. The static rest group did not show a significant change in the ACTH level from $34.45 \pm 17.15 \mathrm{pg} / \mathrm{mL}$ postexercise to $35.65 \pm 18.31 \mathrm{pg} / \mathrm{mL}$ postrecovery. In contrast, although the massage and acupoint acupressure groups did not show a significant decrease in the ACTH level from $26.97 \pm 14.03 \mathrm{pg} / \mathrm{mL}$ postexercise to $21.97 \pm 8.25 \mathrm{pg} / \mathrm{mL}$ postrecovery and from $35.54 \pm 22.86$ $\mathrm{pg} / \mathrm{mL}$ postexercise to $26.35 \pm 12.21 \mathrm{pg} / \mathrm{mL}$ postrecovery, respectively, they both showed a decreasing trend. The aromatherapy group showed a significant decrease in the ACTH level from $32.45 \pm 15.77 \mathrm{pg} / \mathrm{mL}$ postexercise to $24.48 \pm 10.85 \mathrm{pg} / \mathrm{mL}$ postrecovery $(P<0.01)$.

\section{DISCUSSION}

The amount of lactic acid accumulation secondary to exercise depends on its intensity and duration. Lactic acid production is
Table 10. Changes in the adrenocorticotropic hormone level $(\mathrm{pg} / \mathrm{mL})$ from postexercise to postrecovery in each group

\begin{tabular}{lllr}
\hline Group & Postexercise & Postrecovery & \multicolumn{1}{c}{$F(P$-value $)$} \\
\hline Static rest & $34.45 \pm 17.15$ & $35.65 \pm 18.31$ & $2.51(0.147)$ \\
Massage & $26.97 \pm 14.03$ & $21.97 \pm 8.25$ & $4.01(0.076)$ \\
Aromatherapy & $32.45 \pm 15.77$ & $24.48 \pm 10.85$ & $17.67(0.002)$ \\
Acupoint acupressure & $35.54 \pm 22.86$ & $26.35 \pm 12.21$ & $4.78(0.057)$ \\
\hline
\end{tabular}

Values are presented as mean \pm standard deviation.

$F_{\text {group }} *$ time $=4.45(0.048)$

very high in high-intensity exercises (Tesch, 1980). Lactic acid is produced when there is decreased oxygen supply to the muscles, resulting in fatigue, which interferes with the ability to exercise. Therefore, it is important to develop or identify effective ways to remove fatigue substances.

Lactic acid accumulation in the body can be swiftly removed through light exercise or massage rather than rest (Belcastro and Bonen, 1975; Gisolfi et al., 1966; Hermansen and Vaage, 1977). Massage relaxes the muscles and improves oxygen supply to them, which leads to removal of lactic acid and its metabolites to improve muscle fatigue (Cafarelli and Flint, 1992; Callaghan, 1993). Although several studies have questioned the effects of massage on sports performance and fatigue substance removal, it was proven that massage has positive effects on recovery through psychological stabilization (Hemmings et al., 2000; Ogai et al., 2008; Robertson et al., 2004). Mori et al. (2004) also reported that massage improves circulation and body temperature after isometric exercise of the lower back.

In this study, all groups showed decreased postrecovery lactic acid levels compared with their postexercise levels. The largest decrease was observed in the aromatherapy group, followed by the acupoint acupressure, massage, and static rest groups. It seems that natural compounds or plant extracts inhaled to the lungs from aromatherapy would have maintained and facilitated physical and mental homeostasis. It is inferred that these physiological relaxation and psychological stabilization play an important role in lactic acid removal. Jeong et al. (2000) reported that aromatherapy shortens the recovery period by improving arm and leg pain through muscle relaxation. Furthermore, it was reported that aromatherapy improves sports performance. The acupoint acupressure technique involves exerting pressure on the acupoints of the hand, which have regulatory functions on the internal organs. Similar to massage, acupoint acupressure improves circulation and supply of oxygen to the muscles, leading to effective removal of lactic acid.

In this experiment, lactic acids were effectively removed even in 
the static rest group. It is inferred that the athletes possessed an optimized lactic acid removal mechanism owing to adaptation of the cardiovascular system or muscles to constant exercise training.

$\mathrm{CPK}$ and LDH, blood metabolites along with lactic acid, are indirect indicators of cell membrane damage or tissue necrosis. The level of CPK, which is also a fatigue substance, rapidly increases in high-intensity exercises (Apple, 1981; Rich et al., 1977). Clarkson and Tremblay (1988) reported that postexercise muscle pain and decreased muscle strength are related to increased blood $\mathrm{LDH}$ and CPK levels, which are directly proportional to the severity of muscle damage. Since muscle fatigue and pain are influenced by blood CPK and LDH levels, rapid removal of these metabolites is very important for recovery from fatigue. Cha et al. (2006) analyzed changes in the CPK and LDH levels in different recovery methods after a $10-\mathrm{km}$ run and reported that massage and aromatherapy were more effective than static rest in reducing fatigue. Although no significant changes were observed after static rest and massage, aromatherapy and acupoint acupressure significantly reduced the CPK levels. A significant decrease in the $\mathrm{LDH}$ levels was observed in the massage, aromatherapy, and acupoint acupressure groups postrecovery compared with those postexercise. Although the massage group did not show any changes in the CPK levels, the group that received acupoint acupressure, which is similar to massage, showed a significant decrease. It can be inferred that direct stimulation of the skin surface caused local vasodilation, which increased the blood supply to the muscles, consequently leading to the removal of CPK. Furthermore, massage, acupoint acupressure, and aromatherapy improved the recovery of the damaged muscles by rapidly removing $\mathrm{LDH}$.

Excessive muscle fatigue due to high-intensity exercise with short rest intervals decreases the physiological adaptability of the body, and stress decreases muscle function and performance (Barr et al., 1991). Catecholamines, which are produced by the adrenal glands and sympathetic nerves, are closely related to exercise. Postexercise accumulation of lactic acid activates the chemical receptors that affect the hypothalamic-pituitary-adrenal axis (Stainsby et al., 1984).

In this study, a significant decrease in the cortisol, ACTH, and epinephrine levels was observed in the aromatherapy group compared with the postexercise levels. Aromatherapy stimulates the parasympathetic nerves and inhibits the activation of the sympathetic nerves. Furthermore, it stabilizes the autonomic nervous system's balance. Therefore, aromatherapy is known to alleviate symptoms related to imbalance in the autonomic nervous system (Shin et al., 2004). With regard to the release mechanism of the stress hormone catecholamine, Langer (1980) reported that decreased stress and awakening were observed after simultaneously inhaling relaxation oil, which is made of lavender and clary sage known to reduce blood pressure and stress, and stimulation oil, which is made of lemon and rosemary. It can be inferred that inhaled aromatic oil scents affect the adrenal glands. Although the exact mechanism of aromatherapy has not been identified, a decrease in the stress hormone levels could result from chemical components in aroma, inducing physiological activity and stimulating the limbic system, which regulates the autonomic nervous system and emotions, when aromatic oil scents are inhaled and ultimately affect the hormonal system.

Although massage and acupoint acupressure showed a decreasing trend in the postrecovery ACTH levels compared with the postexercise levels, the epinephrine and cortisol levels were not altered significantly. The norepinephrine levels did not significantly differ between the groups. Although massage effectively relaxes the active sympathetic nerves, study results have not always been consistent. This can be because of the fact that massage is very broad in terms of location, duration, and personal sensitivity, and stress hormones are very sensitive to the environment and individuals' physical and psychological differences.

The results showed that aromatherapy using essential oils was the most effective method in improving fatigue and reducing the stress hormone levels. Physical interventions, such as massage and acupoint acupressure, effectively improved stress and fatigue caused by muscle damage and pain.

In conclusion, further studies need to be conducted on a variety of recovery methods, which can approach the psychological and physiological aspects, rather than static rest only, when too much energy is used to the point of an anaerobic state in sports matches, and be applied to the field of sports and individuals' daily life.

\section{CONFLICT OF INTEREST}

No potential conflict of interest relevant to this article was reported.

\section{REFERENCES}

Apple FS. Presence of creatine kinase MB isoenzyme during marathon training. N Engl J Med 1981;305:764-765.

Banfi G, Melegati G, Barassi A, d'Eril GM. Effects of the whole-body cryotherapy on NTproBNP, hsCRP and troponin I in athletes. J Sci Med Sport 2009;12:609-610. 
Barr SI, Costill DL, Fink WJ, Thomas R. Effect of increased training volume on blood lipids and lipoproteins in male collegiate swimmers. Med Sci Sports Exerc 1991;23:795-800.

Belcastro AN, Bonen A. Lactic acid removal rates during controlled and uncontrolled recovery exercise. J Appl Physiol 1975;39:932-936.

Cafarelli E, Flint F. The role of massage in preparation for and recovery from exercise. An overview. Sports Med 1992;14:1-9.

Callaghan MJ. The role of massage in the management of the athlete: a review. Br J Sports Med 1993;27:28-33.

Cha SW, Shin SG, Lim IS. The effect of passive recovery, massage, cold and hot bath and aroma therapy on fatigue metabolic substrate after 10 km running. J Exerc Nutr Biochem 2006;10:37-42.

Christensen NJ, Galbo H. Sympathetic nervous activity during exercise. Annu Rev Physiol 1983;45:139-153.

Clarkson PM, Tremblay I. Exercise-induced muscle damage, repair, and adaptation in humans. J Appl Physiol (1985) 1988;65:1-6.

Gisolfi C, Robinson S, Turrell ES. Effects of aerobic work performed during recovery from exhausting work. J Appl Physiol 1966;21:1767-1772.

Goats GC. Massage-the scientific basis of an ancient art: Part 2. Physiological and therapeutic effects. Br J Sports Med 1994;28:153-156.

Hemmings B, Smith M, Graydon J, Dyson R. Effects of massage on physiological restoration, perceived recovery, and repeated sports performance. Br J Sports Med 2000;34:109-114.

Hermansen L, Vaage O. Lactate disappearance and glycogen synthesis in human muscle after maximal exercise. Am J Physiol 1977;233:E422-429.

Jeong JS, Kwon SJ, Cho TD. A study on the preference factor of pot aromatic herbs. J People Plants Environ 2000;3:69-83.

Langer SZ. Presynaptic regulation of the release of catecholamines. Pharmacol Rev 1980;32:337-362.
Mori H, Ohsawa H, Tanaka TH, Taniwaki E, Leisman G, Nishijo K. Effect of massage on blood flow and muscle fatigue following isometric lumbar exercise. Med Sci Monit 2004;10:CR173-178.

O'Connor PJ, Morgan WP, Raglin JS, Barksdale CM, Kalin NH. Mood state and salivary cortisol levels following overtraining in female swimmers. Psychoneuroendocrinology 1989;14:303-310.

Ogai R, Yamane M, Matsumoto T, Kosaka M. Effects of petrissage massage on fatigue and exercise performance following intensive cycle pedalling. Br J Sports Med 2008;42:834-838.

Rich CL, Woodrow KM, Gillin JC. CPK: relationship of psychological and physical stress. Dis Nerv Syst 1977;38:34-37.

Robertson A, Watt JM, Galloway SD. Effects of leg massage on recovery from high intensity cycling exercise. Br J Sports Med 2004;38:173-176.

Rowsell GJ, Coutts AJ, Reaburn P, Hill-Haas S. Effects of cold-water immersion on physical performance between successive matches in high-performance junior male soccer players. J Sports Sci 2009;27:565573.

Shin YS, Cho YS, Jung YJ. The effects of aromatherapy on autonomic nerve system and physical resistance of a stress. J Korean Biol Nurs Sci 2004; 6:5-17.

Son KC, Song JE, Um SJ, Paek KY, Oh HK, Lee JS, Kim JH. Effect of absorption of essential oils on the changes of arousal and antistress. J Korean Soc Hont Sci 2001;42:614-620.

Stainsby WN, Sumners C, Andrew GM. Plasma catecholamines and their effect on blood lactate and muscle lactate output. J Appl Physiol Respir Environ Exerc Physiol 1984;57:321-325.

Tesch P. Muscle fatigue in man. With special reference to lactate accumulation during short term intense exercise. Acta Physiol Scand Suppl 1980;480:1-40. 